\title{
Inhibition of Staphylococcus epidermidis Biofilms Using Polymerizable Vancomycin Derivatives
}

\author{
McKinley C. Lawson PhD, Kevin C. Hoth BS, \\ Cole A. DeForest BS, Christopher N. Bowman PhD, \\ Kristi S. Anseth PhD
}

Published online: 27 February 2010

(C) The Author(s) 2010. This article is published with open access at Springerlink.com

\begin{abstract}
Background Biofilm formation on indwelling medical devices is a ubiquitous problem causing considerable patient morbidity and mortality. In orthopaedic surgery, this problem is exacerbated by the large number and variety of material types that are implanted. Metallic hardware in conjunction with polymethylmethacrylate (PMMA) bone cement is commonly used.

Questions/purposes We asked whether polymerizable derivatives of vancomycin might be useful to (1) surface modify Ti-6Al-4V alloy and to surface/bulk modify PMMA bone cement to prevent Staphylococcus epidermidis biofilm formation and (2) whether the process altered the compressive modulus, yield strength, resilience, and/or fracture strength of cement copolymers.
\end{abstract}

One or more of the authors (KSA) have received funding from National Science Foundation grant EEC0444771 as well as the Department of Education GAANN program (MCL).

M. C. Lawson, K. C. Hoth, C. A. DeForest, C. N. Bowman Department of Chemical and Biological Engineering,

University of Colorado, Boulder, CO, USA

\section{C. Lawson}

Medical Scientist Training Program (MD/PhD Program), University of Colorado School of Medicine, Denver, CO, USA

K. S. Anseth $(\square)$

Department of Chemical and Biological Engineering, Howard Hughes Medical Institute, University of Colorado, 424 UCB, Boulder, CO 80309, USA

e-mail: kristi.anseth@colorado.edu

\section{C. Lawson}

University of Colorado School of Medicine, UCHSC MSTP

Mailstop B176, Academic Office One, Room L15-2601,

12631 E 17th Avenue, Aurora, CO 80045, USA

e-mail: mckinley.lawson@ucdenver.edu
Methods A Ti-6Al-4V alloy was silanized with methacryloxypropyltrimethoxysilane in preparation for subsequent polymer attachment. Surfaces were then coated with polymers formed from PEG(375)-acrylate or a vancomycinPEG(3400)-PEG(375)-acrylate copolymer. PMMA was loaded with various species, including vancomycin and several polymerizable vancomycin derivatives. To assess antibiofilm properties of these materials, initial bacterial adherence to coated Ti-6Al-4V was determined by scanning electron microscopy (SEM). Biofilm dry mass was determined on PMMA coupons; the compressive mechanical properties were also determined.

Results SEM showed the vancomycin-PEG(3400)acrylate-type surface reduced adherent bacteria numbers by approximately fourfold when compared with PEG(375)acrylate alone. Vancomycin-loading reduced all mechanical properties tested; in contrast, loading a vancomycin-acrylamide derivative restored these deficits but demonstrated no antibiofilm properties. A polymerizable, PEGylated vancomycin derivative reduced biofilm attachment but resulted in inferior cement mechanical properties.

Clinical Relevance The approaches presented here may offer new strategies for developing biofilm-resistant orthopaedic materials. Specifically, polymerizable derivatives of traditional antibiotics may allow for direct polymerization into existing materials such as PMMA bone cement while minimizing mechanical property compromise. Questions remain regarding ideal monomer structure(s) that confer biologic and mechanical benefits.

\section{Introduction}

Biofilms have been referred to as the "hallmark characteristic of periprosthetic joint infection" [8]. One report 
suggests many cases of presumed aseptic prosthetic loosening may actually be the result of undetected biofilms [45]. The antibiotic concentration required for bactericidal activity against sessile organisms can be several orders of magnitude higher than for planktonic bacteria [20], the rule of thumb being 1000 to 1500 times higher [14]. This places a premium on extensive wound irrigation and débridement at the time of surgery followed by lengthy antibiotic therapy.

A classic strategy used in orthopaedic infections, including those of biofilm origin, relies on loading polymethylmethacrylate (PMMA) bone cement with antibiotics that elute in vivo $[4,12,13,17,18,24,26,27$, 29, 35, 37, 41, 42, 49, 50, 66]. Antibiotic-loaded bone cements tend to release entrapped pharmaceuticals in a burst-type fashion and, hence, are effective at delivering high local levels of an antibacterial agent for a short postimplantation period, usually a few days $[4,12,37,41$, 66]. When loaded at high dose, effective antibiotic levels may be maintained in surrounding tissues for several months [1, 30, 41]. However, high-dose loading compromises mechanical behavior of bone cements [12, 26, 35] likely through direct physical changes in material architecture related to the addition of nonpolymerizable species. Antibiotic-loaded PMMA may continue to elute therapeutic agents for weeks or months at suboptimal levels. These problems may be partially overcome by adding water-soluble fillers that increase cement porosity and facilitate antibiotic release, and vacuum processing techniques can lead to more homogenous cement compositions [9, 43, 46]. Unfortunately, bone cement has a surface quite suitable for colonization, and although antibiotic loading can reduce biofilm formation, organisms are still able to grow, for example, on gentamicin-loaded bone cements [33, 61].

Additionally, there is much literature dedicated to polymeric surface modification of metal oxides, including those of titanium, with the goal of blocking protein adhesion and bacterial attachment [15, 22, 28, 40, 54]. Derivatives of poly(ethylene glycol) (PEG) are common in these antibiofouling and antibiofilm strategies [11, 15, 19, 22, 28, 40, 54, 62, 65]. PEG blocks the nonspecific adsorption of proteins, cells, and cellular debris through mechanisms generally attributed to its hydrophilic character and high surface mobility (steric repulsion) [2, 36, 52]. It is particularly attractive in biomaterial systems because PEG is nontoxic [2] and well tolerated at high doses [64]. Polymerizable derivatives of traditional therapeutics potentially offer a convenient advantage over other compounds in that they can be polymerized to implant materials such as Ti-6Al-4V alloy [38] or copolymerized with polymeric biomaterials to provide surface-active antibiotic moieties [39].
We asked whether (1) vancomycin-PEG(3400)-acrylate [VPA(3400)] polymerized to Ti-6Al-4V alloy reduces bacterial attachment with respect to PEG controls; (2) whether the antibiofilm effects of VPA(3400) and two vancomycin-acrylamide derivatives when individually copolymerized with PMMA bone cement would be statistically superior to vancomycin loading in terms of reduced adherent biofilm mass; and (3) whether polymerizable antibiotics when incorporated into PMMA would yield cement constructs with compressive mechanical properties similar to PMMA homopolymer and statistically superior to vancomycin-loaded PMMA.

\section{Materials and Methods}

This study involved the synthesis of three polymerizable vancomycin monomers followed by experimentation along three lines: (1) coating of $\mathrm{Ti}$ alloy with a subset of these monomers followed by assessment of bacterial surface attachment; (2) incorporation of monomers into PMMA bone cement followed by assessment of biofilm proliferation on composite surfaces; and (3) incorporation of monomers into PMMA bone cement followed by compressive mechanical testing (Fig. 1).

All monomer synthesis, purification, and characterization have been described previously $[38,39]$. In a slight modification of those procedures, VPA(3400) was purified by dialysis only. This modification was necessary because of the large quantities of material required for PMMA bone cement biofilm experiments. We obtained three polymerizable vancomycin derivatives. These compounds are illustrated (Fig. 2).

The procedure for functionalizing surgical-grade Ti-6Al-4V alloy bar stock for subsequent polymer attachment has also been described in detail elsewhere [38, 44] but is illustrated briefly (Fig. 3). To form a comonomer solution for polymerization to silanized Ti-6Al-4V, $40 \mathrm{mg}$ VPA(3400) (estimated to be approximately $50 \%$ product with residual PEG[3400]-acrylate and some high-molecular-weight byproducts) was dissolved in $320 \mu \mathrm{L}$ Ar-purged dimethylsulfoxide containing the photoinitiator 2,2-dimethoxy-2-phenyl acetophenone at a concentration of $1 \mathrm{mg} /$ $\mathrm{mL}$ along with $80 \mu \mathrm{L}$ PEG(375)-acrylate. This formulation results in a calculated PEG(375)-acrylate:VPA(3400) ratio of approximately 100:1. When nonantibiotic controls were desired, we omitted the VPA(3400). Surfaces were modified by photoinitiated polymerization of $15 \mu \mathrm{L}$ of a comonomer solution under $45-\mathrm{mW} / \mathrm{cm}^{2}$ intensity, collimated, broad-range, ultraviolet light ( $\mathrm{Hg}$ arc-lamp centered at $365 \mathrm{~nm}$ ) for 900 seconds using a Hybralign Series 200 mask alignment system (Oriel Instruments, Stratford, CT) by techniques detailed elsewhere [31, 38, 56-58]. A 3-day 


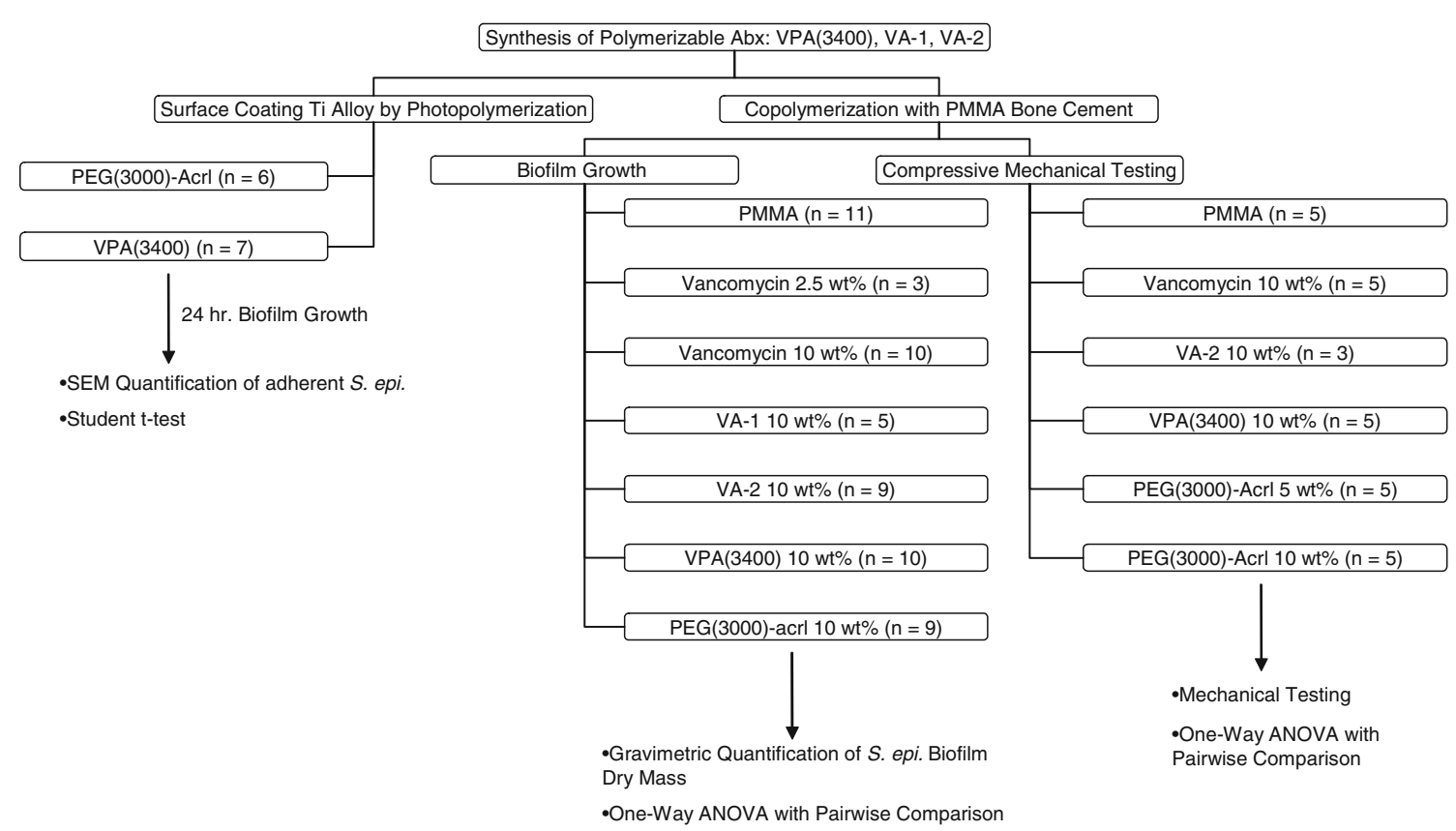

Fig. 1 The flow chart illustrates a basic research design having three separate arms of inquiry following chemical synthesis of polymerizable vancomycin derivatives. The number of samples of each material type examined are shown by "n".

Fig. 2 Vancomycin was modified at the primary amines illustrated. Both PEG-acrylate and acrylamide polymerizable derivatives of vancomycin were synthesized. The PEG-acrylate derivative had a $3400 \mathrm{~g} / \mathrm{mol}$ PEG spacer. For VA-1 and VA-2, the numeral refers to the site of modification, primary or secondary amine, respectively. $R_{1}$ is classically referred to as the vancomycin $V_{3}$ position, and $R_{2}$ is termed the $X_{1}$ position. wash protocol [38] was used to elute any detectable residual monomer, unfunctionalized vancomycin or loosely entangled polymer chains.

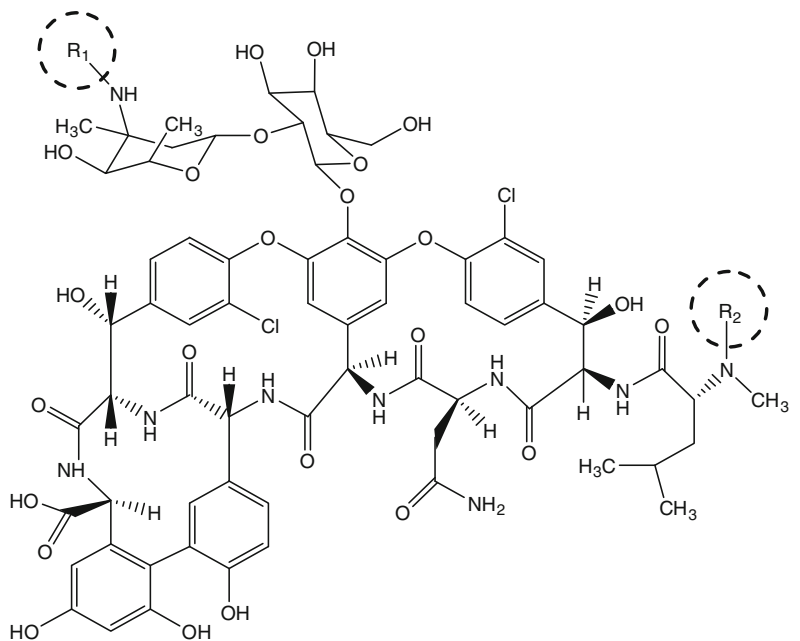

\begin{tabular}{|c|c|c|c|}
\hline & $\operatorname{VPA}(3400)$ & $V A-1$ & VA-2 \\
\hline $\mathrm{R}_{1}=$ & & & \\
\hline $\mathrm{R}_{2}=$ & $\longrightarrow \mathrm{H}$ & $-\mathrm{H}$ & \\
\hline
\end{tabular}

To verify the surfaces were appropriately silanized, $\mathrm{x}$-ray photoelectron spectroscopy (XPS) was used with a $45^{\circ}$ incident monochromatic $\mathrm{X}$-ray beam to characterize 


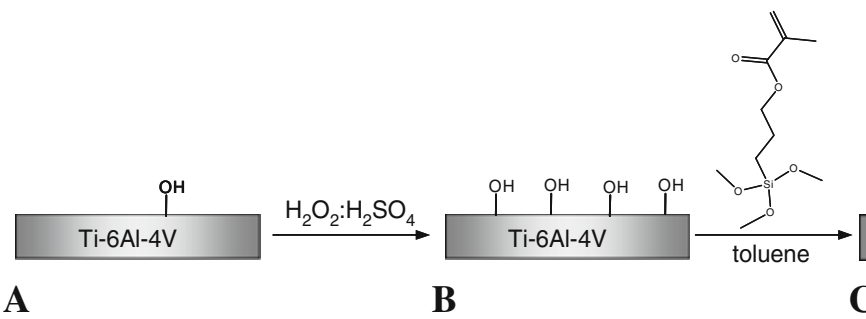

Fig. 3A-D A schematic of the Ti surface modification procedure is shown. (A) The native oxide surface is represented. (B) The native oxide surface is thickened and the number of surface hydroxyl groups are presumably increased. (C) Surface hydroxyls are reacted with methacryloxypropyltrimethoxysilane in anhydrous toluene. This reaction effectively places a layer of methacrylate groups on the surface that can participate in free radical polymerization and anchor polymer chains to the surface. (D) Covering the methacrylated surface

oxidized and silanized surfaces; SEM was also used as a qualitative adjunct to explore the surface features of oxidized surfaces (Fig. 4).

Vancomycin was loaded into "C $\sim$ ment 1" PMMA bone cement (Jorgensen Laboratories, Inc, Loveland, CO) at a concentration of $1 \mathrm{~g}$ vancomycin to $40 \mathrm{~g}$ bone cement powder (2.5 wt \%, a standard, prophylactic loading dose) or at a concentration of $4 \mathrm{~g}$ to $40 \mathrm{~g}$ bone cement powder (10 wt \%, a high, therapeutic loading dose). VPA(3400), VA-1, VA-2, and PEG(3000)-acrylate were loaded at $10 \mathrm{wt} \%$. Cylinders were constructed by first dissolving the desired additive in water and mixing with bone cement powder to create a slurry. The slurry was then flash-frozen using liquid nitrogen and lyophilized to recover a homogeneous powder. Bone cement cylinders were polymerized by addition of monomer liquid according to the manufacturer's directions. Cylinders of dimensions $10 \mathrm{~mm} \times 5 \mathrm{~mm}$ (height $\times$ diameter) were formed using a Teflon mold.

Substrates (polymer-coated Ti alloy) were placed in $50 \mathrm{~mL}$ brain heart infusion (BHI) medium, and the medium was inoculated with Staphylococcus epidermidis ATCC 35984 (clinical, biofilm-forming isolate). BHI medium was used in previous studies of polymerizable vancomycin derivatives $[38,39]$ and, for consistency, was used here.

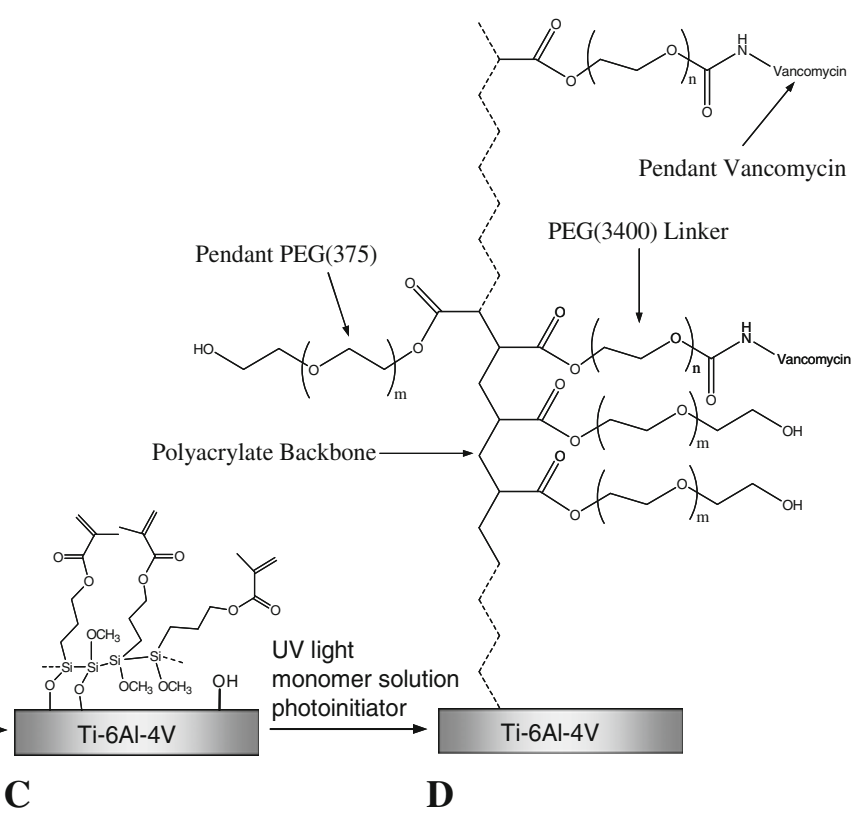

with a monomer solution containing a polymerizable antibiotic (VPA[3400] in this case), another polymerizable species (PEG[375]acrylate), and a photoinitiator followed by exposure to ultraviolet radiation results in polymerization. A fraction of the polymer chains are covalently attached to the surface, albeit in a geometrically more complex structure than that shown here. In this reaction scheme, a polyacrylate backbone is formed with pendant VPA(3400) and PEG(375). Here, assuming ideal polymerization, $\mathrm{n}=9$ and $\mathrm{n}=80$.

Samples were incubated on a rotary shaker at $100 \mathrm{rpm}$ at $37^{\circ} \mathrm{C}$. Polymer-coated Ti samples were allowed to incubate for 24 or 72 hours. Twenty-four-hour samples were removed, rinsed with copious amounts of water to wash away unbound organisms, and prepared for SEM. Seventytwo-hour specimens were inspected visually. The SEM preparatory procedure consisted of 1-hour fixation in 10\% (v/v) phosphate-buffered formalin (Fisher Scientific, Kalamazoo, MI) followed by an ethanol dehydration series: 15 minutes in 50:50 ethanol: $\mathrm{H}_{2} \mathrm{O}, 15$ minutes in 75:25 ethanol: $\mathrm{H}_{2} \mathrm{O}, 15$ minutes in 95:5 ethanol: $\mathrm{H}_{2} \mathrm{O}$, and 30 minutes in $100 \%$ ethanol. The samples were then placed in hexamethyldisilazane (Electron Microscopy Sciences, Hatfield, PA) for 1 hour 45 minutes, removed, frozen, lyophilized, and gold-coated. SEM images were obtained at 750x magnification using a JSM-6480LV system (JOEL Ltd, Tokyo, Japan). A minimum of 10 random images was taken of each sample coupon by panning the microscope to non-predetermined regions about the test coupon and then quantifying adherent organisms. Organisms were not visible during the panning procedure, only when the microscope came to a complete stop. Adherent Staphylococcal organisms were counted, and an average surface density was calculated for each coupon using area measurements from ImageJ Version 1.33u software (National 


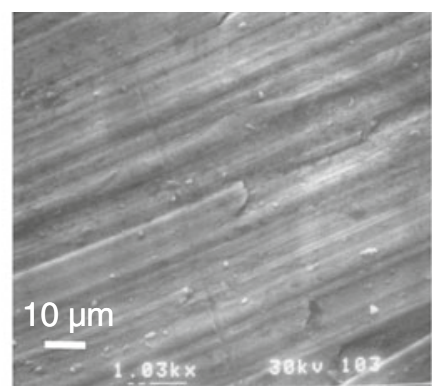

Native Oxide Surface A

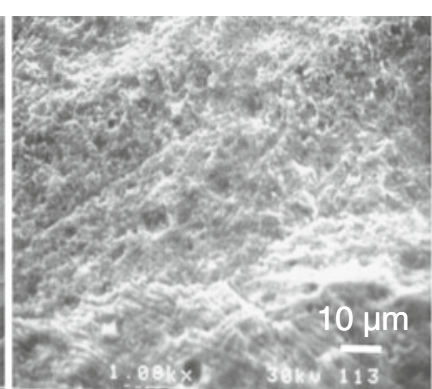

Chemically Oxidized Surface

B

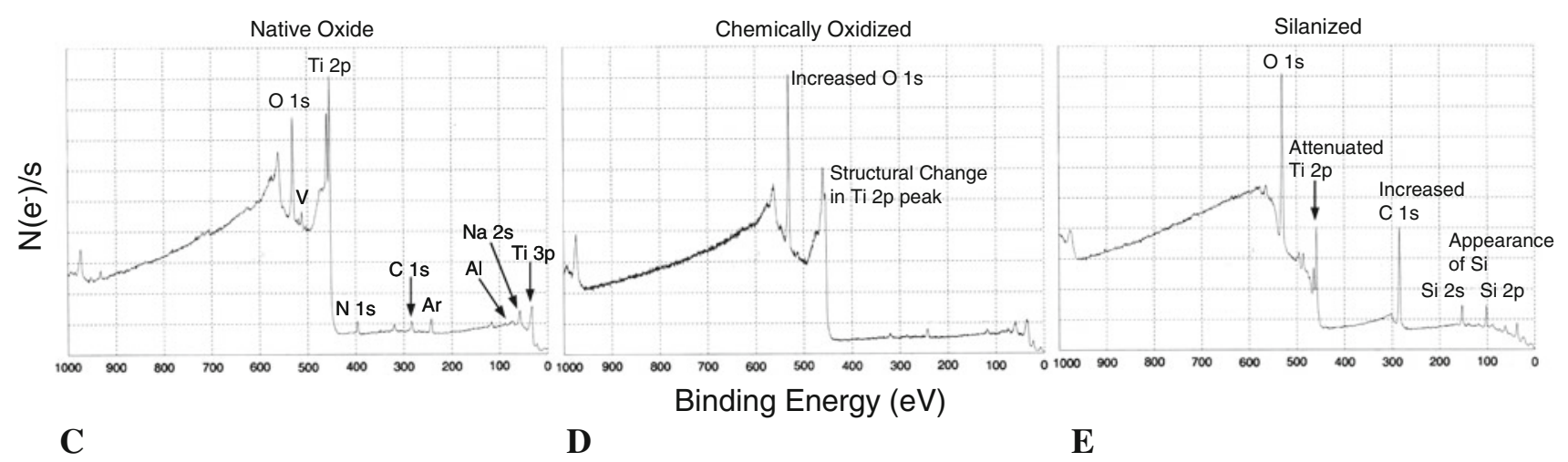

Fig. 4A-E Scanning electron microscopy $(\times 1000)$ provides a qualitative means of visualizing changes in Ti-6Al-4V surface structure (A) before and (B) after oxidation with $\mathrm{H}_{2} \mathrm{SO}_{4}: \mathrm{H}_{2} \mathrm{O}_{2}$ solution. This oxidation procedure serves to increase the number of surface hydroxyl groups available for subsequent functionalization with a silane reagent. XPS allows for elemental characterization of Ti-6Al-4V surfaces having undergone modification as described in Fig. 3. The number of electrons ejected per second is plotted against electron binding energy. (C) The native oxide is shown. Oxygen and titanium are the primary elements present, but some level of $\mathrm{N}, \mathrm{C}, \mathrm{Na}$, and $\mathrm{Cl}$

Institutes of Health, Bethesda, MD). This approach was repeated for each Ti sample of varying surface type.

PMMA cylinders were incubated analogously except they were transferred to fresh media every 22 hours. Twenty-two hours was chosen as a time point for media collection as this marked the onset of bacterial suspension turbidity, and there was concern for inappropriate bacterial death with incubation under turbid conditions. At 22, 44, 66, and 88 hours, cylinders were collected, freeze-dried before adherent biofilm mass was determined gravimetrically (biofilm dry weight) to the closest $1 / 10$ milligram using a standard analytical balance and a modification of methods described elsewhere [59]. We used 4-day growth data for comparing surface types. Vancomycin-loaded cylinders released active antibiotic for the first 22 hours at levels sufficient to inhibit bacterial growth in the incubation vessel as these vancomycin-containing vessels did not go on to reach turbidity if allowed to incubate further. However, if fresh media were supplied, bacterial growth contamination exists as well. Residual Ar is present from the XPS surface preparation procedure. (D) The oxidation process increased the oxide content of the surface and possibly changed the structure of the Ti $2 p$ peak. These findings are consistent with oxide replacement of Ti-6Al-4V in the surface layer. (E) Silanization leads to a further attenuated Ti 2 p peak, an increased $\mathrm{C} 1 \mathrm{~s}$ peak, and the appearance of Si $2 \mathrm{~s}$ and Si 2 p peaks. This collection of observations is consistent with the formation of a siloxane layer over the Ti-6Al-4V oxidized surface.

commenced over subsequent time intervals. Accordingly, for vancomycin-loaded samples, reported time points were adjusted by subtracting 22 hours and represent hours after observed burst elution.

PMMA and PMMA-composite compressive mechanical properties were measured using an MTS 858 MiniBionix II system (MTS Systems Corp, Eden Prairie, MN) with a platen speed of $1 \mathrm{~mm} / \mathrm{min}$. Stress strain data were analyzed external to the system software. Compressive modulus was calculated as the slope of the elastic deformation region using a standard linear least squares fit. Yield strength (stress at the transition between elastic and plastic deformation) was calculated using a 0.002 offset method. Resilience was calculated as the area under the stress-strain curve up to yield strength. Fracture strength, when applicable, was taken as the stress at catastrophic failure.

We determined by SEM differences in the average number of adherent $\mathrm{S}$. epidermidis organisms between $\mathrm{Ti}$ alloy surfaces coated with PEG(375)-acrl $(\mathrm{n}=6)$ and 
VPA(3400)-PEG(375)-acrl $(\mathrm{n}=7)$ using the Student's t-test. We determined differences in adherent biofilm dry mass between PMMA cylinders $(\mathrm{n}=11)$, PMMA cylinders incorporating vancomycin at $2.5 \mathrm{wt} \% \quad(\mathrm{n}=3)$, vancomycin at $10 \mathrm{wt} \%(\mathrm{n}=10), \operatorname{VPA}(3400)$ at $10 \mathrm{wt} \%$ $(\mathrm{n}=10), \mathrm{VA}-1$ at $10 \mathrm{wt} \%(\mathrm{n}=5), \mathrm{VA}-2$ at $10 \mathrm{wt} \%$ $(n=9)$, or PEG(3000)-acrylate at $10 \mathrm{wt} \%(n=9)$ using the one-way analysis of variance (ANOVA) in combination with the Tukey Test for pairwise comparisons. We determined differences in compressive modulus, yield strength, resilience, fracture strength, and strain at fracture between PMMA coupons $(\mathrm{n}=5)$, PMMA coupons incorporating vancomycin $10 \mathrm{wt} \%(\mathrm{n}=5), \operatorname{VPA}(3400) 10 \mathrm{wt} \%(\mathrm{n}=5)$, PEG(3000)-Acrl $5 \mathrm{wt} \%(\mathrm{n}=5)$, PEG(3000)-Acrl $10 \mathrm{wt} \%$ $(\mathrm{n}=5)$, and VA-2 $10 \mathrm{wt} \%(\mathrm{n}=3)$ using the one-way ANOVA in combination with the Tukey test for pairwise comparisons. Levine's test was used to check the assumption of equal sample variances, and the
Kolmogorov-Smirnov test along with visual examination of normal probability plots was used to verify data normality for all ANOVA analyses.

\section{Results}

In the 24-hour growth experiment to assess the initial attachment of organisms to the polymer-coated Ti alloy surfaces the SEM observations followed by quantification of adherent organisms suggested the VPA(3400) copolymer reduced $(p=0.007)$ the number of organisms by approximately fourfold relative to the PEG(375)-acrylate surface (Fig. 5). The bare oxide surface was covered with a confluent layer of organisms, making enumeration impractical. In a separate 72-hour growth experiment with oxidized Ti-6Al-4V alloy, PEG(375)-acrylate coated alloy, and VPA(3400)-PEG(375)-acrylate coated alloy, the bare

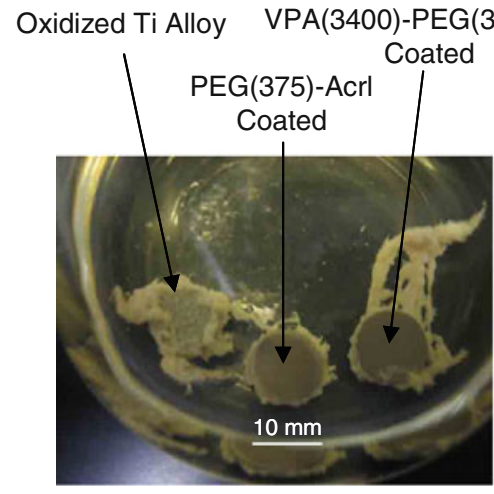

A

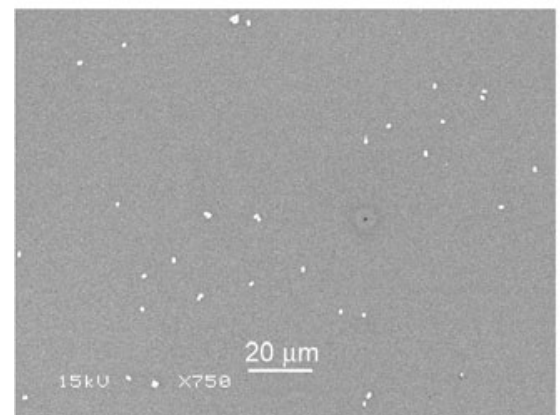

D

Fig. 5A-E (A) Three Ti alloy discs exposed to biofilm-forming Staphylococcus epidermidis culture for $66 \mathrm{hrs}$ are shown. The composition of the surface coatings (top surface only) are illustrated (arrows). (B) The same three discs are shown from a second perspective. Bare oxide surface is completely covered with biofilm. The coated portion of the PEG(375)-acrylate disc is visually clean. The coated portion of the VPA(3400)-PEG(375)-acrylate disc is visually clean as well. These figures clearly demonstrate the antibiofilm properties of PEG-type coatings. (C) A scanning electron microscopy (SEM) image of S. epidermidis biofilm at

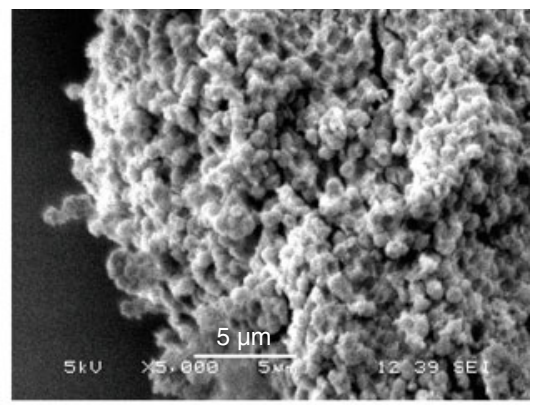

C

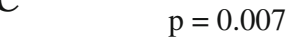

$1.6 \pm 0.7 \times 10^{5} / \mathrm{cm}^{2}$

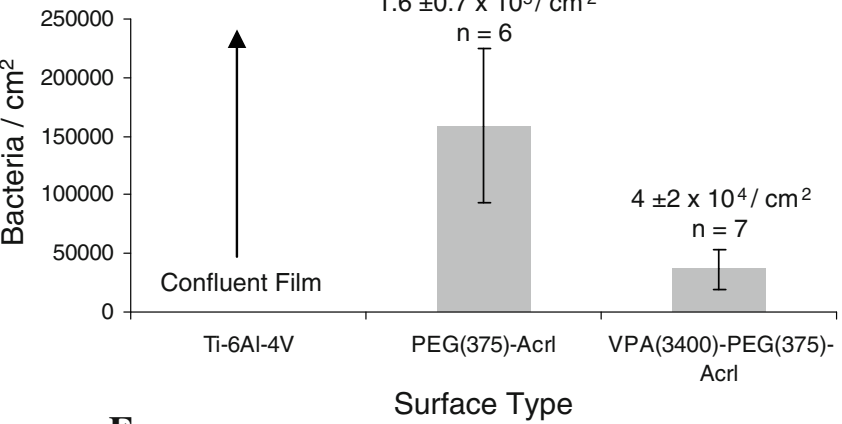

$\mathbf{E}$

$\times 5000$ magnification is shown (66 hours in culture). Cocci are apparent as is glycocalyx. (D) An SEM image at $\times 750$ magnification shows attachment of S. epidermidis on PEG(375)-acrylatecoated $\mathrm{Ti}$ alloy ( 24 hours in culture). Images of this sort (without obscuring glycocalyx) were used to quantify attached organisms on both PEG and VPA(3400) surfaces. The white spots are bacteria. (E) Both surfaces reduced the number of attached organisms. However, data suggest that having VPA(3400) in the copolymer reduces bacterial attachment more effectively than PEG(375)acrylate alone. 
oxide surface was completely covered with biofilm organisms and glycocalyx (Fig. 5A-B). Both polymercoated surfaces were visually clear of bacteria.

In separate experiments with PMMA-antibiotic composites, after 4 days under growth conditions, the mass of adherent organisms and glycocalyx was reduced on $10 \mathrm{wt} \%$ VPA(3400)-PMMA and 10 wt\% PEG(3000)-acrylatePMMA relative to PMMA controls $(\mathrm{p}<0.01$ for both comparisons). Ten wt $\%$ VA-1 and VA- 2 composites were associated with a similar mass of adherent organisms and glycocalyx on PMMA. Bacteria colonized and grew on high-dose vancomycin-loaded PMMA (10 wt $\%$ vancomycin), and biofilm mass showed an exponential increase with time (Fig. 6A). Low-dose or high-dose loading of
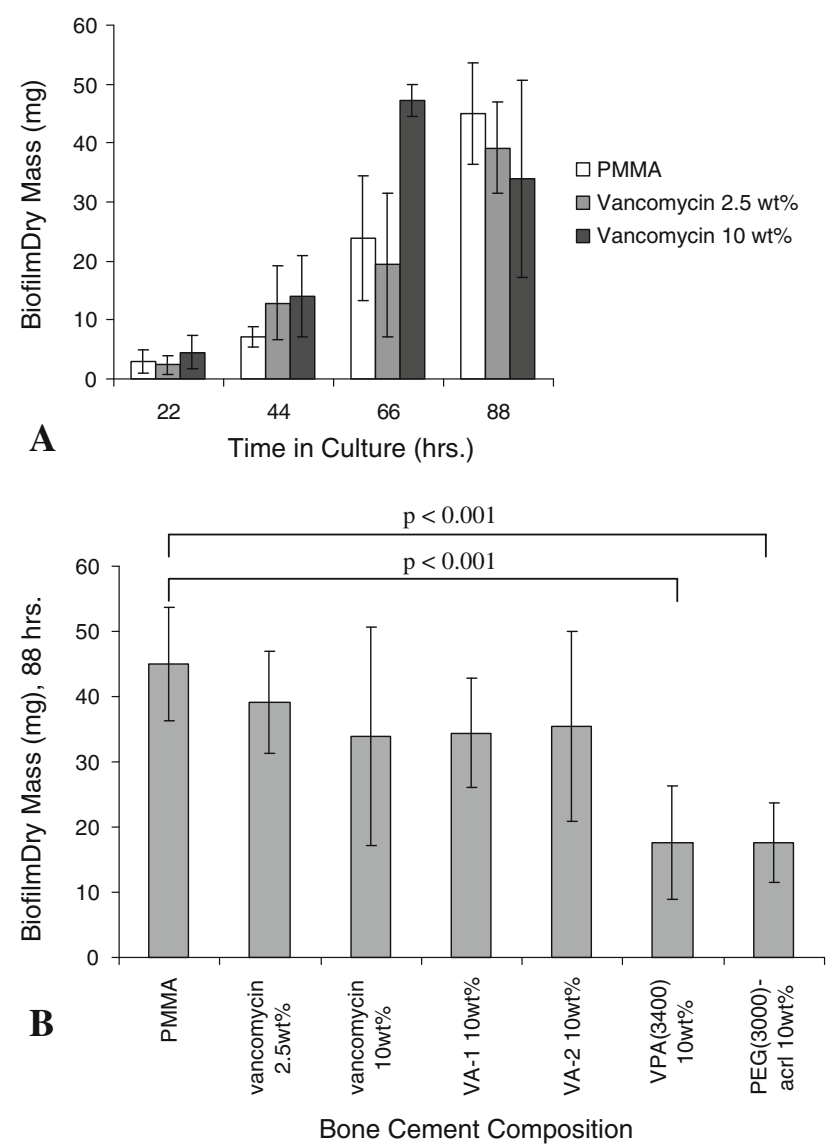

Fig. 6A-B (A) Staphylococcus epidermidis biofilms readily proliferate on PMMA bone cement and vancomycin-loaded PMMA bone cement. Even high-dose vancomycin loading does not prevent biofilm formation after initial burst release, although it tends to increase experimental variability. This outcome may be related to inconsistent elution of small amounts of entrapped antibiotic. (B) Various species were added to PMMA bone cement to evaluate antibiofilm activity. Eighty-eight-hour time points are shown. Neither of the vancomycinacrylamides were effective. Both VPA(3400) and PEG(3000)-acrylate reduced adherent organisms with respect to PMMA. These observations suggest ethylene glycol functionalities are largely responsible for the observed antibiofilm properties in this assay. vancomycin did not reduce biofilm mass. However, both 10 wt \% VPA(3400)-PMMA and $10 \mathrm{wt} \%$ PEG(3000)-acrylatePMMA had less biofilm than high-dose vancomycin cement ( $\mathrm{p}=0.08$ and $\mathrm{p}=0.09$, respectively) (Fig. 6B).

We observed adverse mechanical effects of adding vancomycin to PMMA bone cement and also the potential mechanical property advantages of adding a polymerizable antibiotic derivative to PMMA (Table 1; Fig. 7A). Vancomycin loaded at $10 \mathrm{wt} \%$ in PMMA bone cement decreased the compressive modulus by $20 \%(\mathrm{p}=0.01)$, yield strength by $16 \%(\mathrm{p}<0.0001)$, resilience by $17 \%$ $(\mathrm{p}=0.02)$, fracture strength by $41 \%(\mathrm{p}<0.0001)$, and strain at fracture by $35 \%(\mathrm{p}=0.02)$. Conversely, VA-2 did not decrease any mechanical property and rather increased $(p=0.1)$ the compressive modulus $13 \%$ with respect to PMMA. Relative to PMMA, VPA(3400) decreased the compressive modulus by $36 \%(\mathrm{p}<0.001)$, yield strength by $38 \%(\mathrm{p}<0.001)$, and resilience by $43 \%(\mathrm{p}<0.001)$. Relative to PMMA, PEG(3000)-acrylate incorporated at 10 wt $\%$ decreased the same mechanical properties to a similar degree (Table 1).

\section{Discussion}

Biofilm-forming organisms continue to be a central concern in orthopaedic procedures which involve the placement of metallic hardware in conjunction with PMMA bone cement. We present initial work to evaluate the usefulness of vancomycin-PEG-acrylate and vancomycin-acrylamide species for the inhibition of $\mathrm{S}$. epidermidis biofilm formation on both Ti-6Al-4V orthopaedic alloy and on PMMA bone cement.. We evaluated: (1) whether VPA(3400) polymerized to Ti-6Al-4V alloy reduces bacterial attachment; (2) the antibiofilm effects (reduced biofilm mass) of VPA(3400) and two vancomycin-acrylamide derivatives when individually copolymerized with PMMA bone cement; and (3) the compressive mechanical effects of adding polymerizable antibiotics to PMMA bone cement.

We acknowledge limitations to our experiment. First is that the biofilm growth conditions presented may not reflect those encountered in vivo. A biofilm bioreactor might offer a more sophisticated approach to simulating growth conditions [3, 10, 34]. However, it is inherently difficult to define the complex milieu of an infection site, and the assays used here were sufficient to define differences between material types. Second, the traditional method of quantifying adherent biofilm is by measurement of viability by prior desorption (ultrasonication) and subsequent agar plating [25], though there is often considerable variability in the absolute bacterial count obtained by different methods [48]. Quantification by SEM is often limited [25] secondary to problems of bacterial 
Table 1. Compressive mechanical properties for PMMA bone cement with various additives are shown. VA-2 composite properties are very similar to those of PMMA. Species with PEG functionalities lead to mechanical property compromise

\begin{tabular}{lcllll}
\hline Material & $\begin{array}{l}\text { Compressive } \\
\text { modulus (MPa) }\end{array}$ & $\begin{array}{l}\text { Yield strength } \\
(\mathrm{MPa})\end{array}$ & Resilience $\left(\mathrm{J} / \mathrm{cm}^{3}\right)$ & $\begin{array}{l}\text { Fracture } \\
\text { strength }(\mathrm{MPa})\end{array}$ & $\begin{array}{l}\text { Strain at } \\
\text { fracture }(\%)\end{array}$ \\
\hline PMMA & $25 \pm 1(100 \%)$ & $85 \pm 3(100 \%)$ & $3.0 \pm 0.2(100 \%)$ & $96 \pm 13(100 \%)$ & $31 \pm 7(100 \%)$ \\
Vancomycin 10wt\% & $20 \pm 1(80 \%)$ & $71 \pm 2(84 \%)$ & $2.5 \pm 0.3(83 \%)$ & $57 \pm 5(59 \%)$ & $20 \pm 3(65 \%)$ \\
VA-2 10wt\% & $28.2 \pm 0.4(113 \%)$ & $87 \pm 1(102 \%)$ & $2.8 \pm 0.3(93 \%)$ & $90 \pm 2(94 \%)$ & $31 \pm 3(100 \%)$ \\
VPA(3400) 10wt\% & $16 \pm 3(64 \%)$ & $53 \pm 2(62 \%)$ & $1.7 \pm 0.2(57 \%)$ & $76 \pm 8(79 \%)^{*}$ & $34 \pm 2(110 \%)^{*}$ \\
PEG(3000)-Acrl 5wt\% & $20.7 \pm 0.5(83 \%)$ & $59 \pm 2(69 \%)$ & $1.9 \pm 0.1(63 \%)$ & $72 \pm 6(75 \%)^{*}$ & $33 \pm 3(106 \%)^{*}$ \\
PEG(3000)-Acrl 10wt\% & $15 \pm 1(60 \%)$ & $44 \pm 4(52 \%)$ & $1.4 \pm 0.2(47 \%)$ & $50 \pm 7(52 \%)^{*}$ & $27 \pm 6(87 \%)^{*}$ \\
\hline
\end{tabular}

Asterisks indicate materials with potential microcracking.
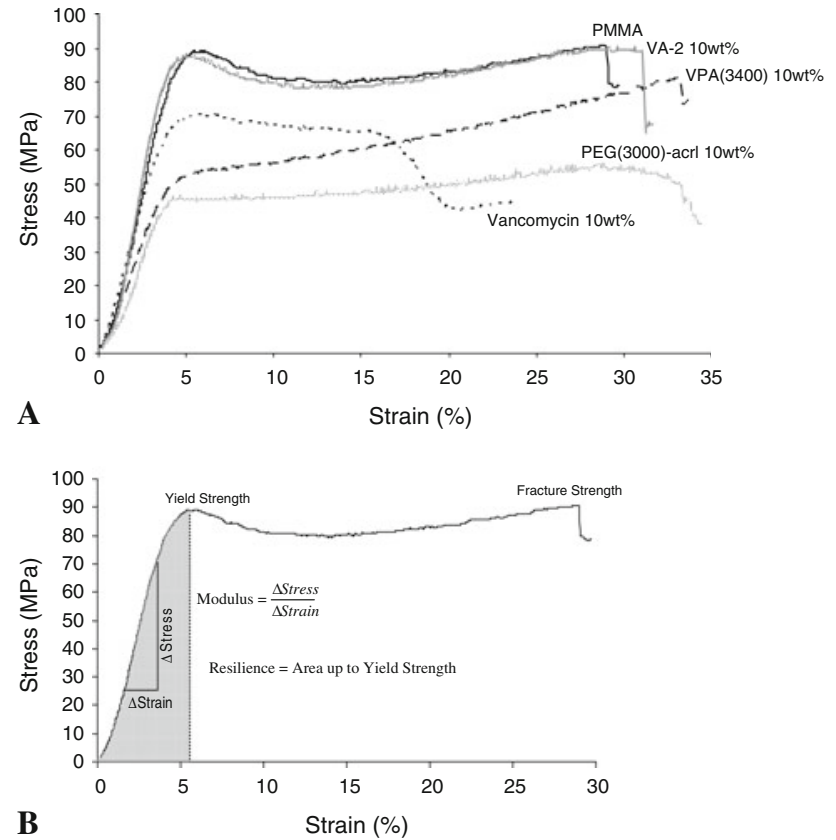

Fig. 7A-B (A) Representative stress-strain curves are shown for PMMA bone cement with various additives (compressive tests). Loading vancomycin-acrylamide-2 (VA-2) at $10 \mathrm{wt} \%$ results in properties similar to those of PMMA, suggesting that polymerizable antibiotic derivatives may avoid some of the problems classically encountered with high-dose vancomycin loading. However, adding $\operatorname{VPA}(3400)$ at $10 \mathrm{wt} \%$ severely compromises mechanical properties and may lead to microcracking. This behavior is likely the result of the bulky PEG linker or its hydrophilicity. It is expected that an optimum number of ethylene glycol repeats would result in properties between those of VA-2 and VPA(3400) while at the same time offer antibiofilm properties. (B) Key mechanical properties are illustrated.

enumeration arising from bacterial agglomerates and matrix-embedded bacteria $[25,55,60]$ and from the possibility that some of the biofilm structure will be lost during preparation [23, 63]. For this reason, our SEM quantification methods were limited to measurement of initial bacterial attachment where extensive glycocalyx was not present and where relative bacterial surface density was low. We expect the reported bacterial surface densities (Fig. 5) to be technique dependent as with other methods [48]. Dry mass has also been used to quantify biofilm proliferation [51, 59]; however, the gravimetric assay used here to evaluate adherent biofilm mass on PMMA surfaces does not provide adequate precision for discriminating between the effects of VPA(3400) and PEG(3000)-acrylate. Third, although we demonstrated various statistically significant effects attributable to polymerizable antibiotic species, whether these effects will have clinical importance is a question for future work.

In experiments with polymer-coated $\mathrm{Ti}$ alloy, VPA(3400) appears to add an additional level of protection to PEG-type coatings (Fig. 5). Surface-contact killing may contribute to the decreased number of adherent bacteria during the initial stages of biomaterial colonization. It is likely this period is critical in true physiological infections in which the bacterial load in the surrounding fluids is generally expected to be low. In comparison, a recently described antimicrobial technique involves the covalent attachment of an antibiotic (presumably a monolayer) to titanium [5-7, 21, 32, 47]. Building on surface modification methods described by Nanci et al. [44], the authors were able to attach vancomycin to titanium via two aminoethoxyethoxyacetate linkers. One study suggested Staphylococcus aureus attachment may be blocked using this surface-modification platform [7]. However, because aminoethoxyethoxyacetate linkers (sold commercially as "Mini-PEG") effectively put a thin PEG layer on a surface (four ethylene glycol units), some of the observed antibiofilm properties may be related to the linker chemistry. Another study reported as few as four ethylene glycol repeats can provide antibiofouling properties for 3 weeks or longer with some cell types [22].

The data show incorporation of PEG moieties into the PMMA architecture retards but ultimately does not prevent biofilm adherence. This effect may be related to blockage of initial bacterial attachment, as suggested in other studies with PMMA [16, 53], but may be overcome as the surface is saturated with bacterial glycocalyx and cellular debris. 
Neither of the vancomycin-acrylamide derivatives showed an antibiofilm effect. This behavior is consistent with previous observations [39] suggesting the PEG linker is critical for antibacterial activity once vancomycin derivatives are polymerized from solid substrates. In an alternative approach, a quaternary amine dimethacrylate (QADMA) species was copolymerized with PMMA bone cement, and antibiofilm properties against Escherichia coli were examined [16, 53], but no quantification of adherent organisms was undertaken. Data suggested QADMA blocked the attachment of Escherichia coli; whether this was related to the killing of microorganisms is less clear.

Mechanical testing of antibiotic-loaded bone cements (Table 1) confirms that adding vancomycin at $10 \mathrm{wt} \%$ decreases compressive modulus, yield strength, resilience, and fracture strength, which is consistent with previous reports [12, 26, 35]; for example, Klekamp et al. [35] showed that, in fatigue tests, loading vancomycin at 7.5 wt $\%$ decreased the number of cycles to failure by $50 \%$. Substituting the acrylamide-modified vancomycin derivative VA-2 at $10 \mathrm{wt} \%$ restores all measured mechanical deficits and may actually increase the compressive modulus. These improvements likely occur because the acrylamide functionality copolymerizes with methacrylate groups during bone cement curing, whereas vancomycin does not. Conversely, vancomycin may leave gross structural cavities in the cement or act as a plasticizer. Unfortunately, VA-2 and VA-1 were not effective at blocking biofilm formation in the assay presented here, suggesting it was the PEG functionality that conferred antibiofilm properties and also mechanically compromised the cements. PEG is known to confer resistance to cellular or protein attachment $[19,22,65]$, and the PEG tether is reportedly important for increasing surface-based activity of VPA-type species [39]. There may be some optimal number of ethylene glycol units that confers adequate antibacterial activity without sacrificing bone cement mechanical integrity.

Data with coated Ti alloy surfaces suggest copolymerizing a PEGylated vancomycin species, VPA(3400), with PEG(375)-acrylate is more effective than PEG alone at blocking S. epidermidis biofilms. The PEG spacer itself likely contributes to the antibiofilm effect, but SEM data indicate the pendant vancomycin molecule improves the antimicrobial effect under some growth conditions. Loading PMMA bone cement with certain polymerizable vancomycin derivatives may eventually be useful for retarding biofilm adherence without compromising mechanical properties, although the current formulations did one or the other, but not both. A vancomycin-acrylamide additive resulted in compressive mechanical properties almost identical to PMMA controls but did not inhibit biofilm growth. VPA(3400) reduced biofilm growth but compromised mechanical properties. Experiments described here should facilitate the development of new antibiofilm biomaterial surfaces.

Acknowledgments We thank J. McCormick for assistance with XPS surface characterization.

Open Access This article is distributed under the terms of the Creative Commons Attribution Noncommercial License which permits any noncommercial use, distribution, and reproduction in any medium, provided the original author(s) and source are credited.

\section{References}

1. Adams K, Couch L, Cierny G, Calhoun J, Mader JT. In vitro and in vivo evaluation of antibiotic diffusion from antibioticimpregnated polymethylmethacrylate beads. Clin Orthop Relat Res. 1992;278:244-252.

2. Alcantar NA, Aydil ES, Israelachvili JN. Polyethylene glycolcoated biocompatible surfaces. J Biomed Mater Res. 2000;51: 343-351.

3. An UH, Mcglohorn JB, Bednarski BK, Martin KL, Friedman RJ. An Open Channel Flow Chamber for Characterizing Biofilm Formation on Biomaterial Surfaces. Methods Enzymol. 2001;337: 79-88.

4. Anguita-Alonso P, Rouse MS, Piper KE, Jacofsky DJ, Osmon DR, Patel R. Comparative study of antimicrobial release kinetics from polymethylmethacrylate. Clin Orthop Relat Res. 2006;445: 239-244.

5. Antoci V, Jr., Adams CS, Hickok NJ, Shapiro IM, Parvizi J. Vancomycin bound to Ti rods reduces periprosthetic infection: preliminary study. Clin Orthop Relat Res. 2007;461:88-95.

6. Antoci V, Jr., Adams CS, Parvizi J, Ducheyne P, Shapiro IM, Hickok NJ. Covalently attached vancomycin provides a nanoscale antibacterial surface. Clin Orthop Relat Res. 2007;461:81-87.

7. Antoci V, Jr., King SB, Jose B, Parvizi J, Zeiger AR, Wickstrom E, Freeman TA, Composto RJ, Ducheyne P, Shapiro IM, Hickok NJ, Adams CS. Vancomycin covalently bonded to titanium alloy prevents bacterial colonization. J Orthop Res. 2007;25:858-866.

8. Antonios V, Berbari E, Osmon D. Treatment protocol of infections of orthopedic devices. In: Pace JL, Rupp ME, Finch RG, eds. Biofilms, Infection, and Antimicrobial Therapy. Boca Raton, FL: CRC Press; 2006:449-478.

9. Askew MJ, Kufel MF, Fleissner PR, Jr., Gradisar IA, Jr., Salstrom SJ, Tan JS. Effect of vacuum mixing on the mechanical properties of antibiotic-impregnated polymethylmethacrylate bone cement. J Biomed Mater Res. 1990;24:573-580.

10. Bott T, Grant DM. Biofilms in Flowing Systems. Methods Enzymol. 2001;337:88-103.

11. Boulmedais F, Frisch B, Etienne O, Lavalle P, Picart C, Ogier J, Voegel JC, Schaaf P, Egles C. Polyelectrolyte multilayer films with pegylated polypeptides as a new type of anti-microbial protection for biomaterials. Biomaterials. 2004;25:2003-2011.

12. Bourne RB. Prophylactic use of antibiotic bone cement: an emerging standard-in the affirmative. J Arthroplasty. 2004;19:69-72.

13. Brien WW, Salvati EA, Klein R, Brause B, Stern S. Antibiotic impregnated bone cement in total hip arthroplasty. An in vivo comparison of the elution properties of tobramycin and vancomycin. Clin Orthop Relat Res. 1993;296:242-248.

14. Costerton JW, Stewart PS, Greenberg EP. Bacterial biofilms: a common cause of persistent infections. Science. 1999;284:13181322. 
15. Dalsin JL, Lin L, Tosatti S, Voros J, Textor M, Messersmith PB. Protein resistance of titanium oxide surfaces modified by biologically inspired mPEG-DOPA. Langmuir. 2005;21:640-646.

16. Deb S, Doiron R, DiSilvio L, Punyani S, Singh H. PMMA bone cement containing a quaternary amine comonomer with potential antibacterial properties. J Biomed Mater Res B Appl Biomater. 2008;85:130-139.

17. DiMaio FR, O'Halloran JJ, Quale JM. In vitro elution of ciprofloxacin from polymethylmethacrylate cement beads. J Orthop Res. 1994;12:79-82.

18. Donati D, Biscaglia R. The use of antibiotic-impregnated cement in infected reconstructions after resection for bone tumours. J Bone Joint Surg Br. 1998;80:1045-1050.

19. Dong B, Jiang H, Manolache S, Wong AC, Denes FS. Plasmamediated grafting of poly(ethylene glycol) on polyamide and polyester surfaces and evaluation of antifouling ability of modified substrates. Langmuir. 2007;23:7306-7313.

20. Dunne WM, Jr. Bacterial adhesion: seen any good biofilms lately? Clin Microbiol Rev. 2002;15:155-166.

21. Edupuganti OP, Antoci V, Jr., King SB, Jose B, Adams CS, Parvizi J, Shapiro IM, Zeiger AR, Hickok NJ, Wickstrom E. Covalent bonding of vancomycin to Ti6Al4V alloy pins provides long-term inhibition of Staphylococcus aureus colonization. Bioorg Med Chem Lett. 2007;17:2692-2696.

22. Fan X, Lin L, Messersmith PB. Cell fouling resistance of polymer brushes grafted from $\mathrm{Ti}$ substrates by surface-initiated polymerization: effect of ethylene glycol side chain length. Biomacromolecules. 2006;7:2443-2448.

23. Fassel TA, Edmiston CE. Bacterial biofilms: strategies for preparing glycocalyx for electron microscopy. Methods Enzymol. 1999;310:194-203.

24. Gerhart TN, Roux RD, Hanff PA, Horowitz GL, Renshaw AA, Hayes WC. Antibiotic-loaded biodegradable bone cement for prophylaxis and treatment of experimental osteomyelitis in rats. J Orthop Res. 1993;11:250-255.

25. Hannig C, Follo M, Hellwig E, Al-Ahmad A. Visualization of adherent micro-organisms using different techniques. J Med Microbiol. 2010;59:1-7.

26. Hanssen AD. Prophylactic use of antibiotic bone cement: an emerging standard-in opposition. J Arthroplasty. 2004;19:73-77.

27. Hanssen AD, Rand JA, Osmon DR. Treatment of the infected total knee arthroplasty with insertion of another prosthesis. The effect of antibiotic-impregnated bone cement. Clin Orthop Relat Res. 1994;309:44-55.

28. Harris LG, Tosatti S, Wieland M, Textor M, Richards RG. Staphylococcus aureus adhesion to titanium oxide surfaces coated with non-functionalized and peptide-functionalized poly $(\mathrm{L}-$ lysine)-grafted-poly(ethylene glycol) copolymers. Biomaterials. 2004;25:4135-4148.

29. Heck D, Rosenberg A, Schink-Ascani M, Garbus S, Kiewitt T. Use of antibiotic-impregnated cement during hip and knee arthroplasty in the United States. J Arthroplasty. 1995;10:470475.

30. Hoff SF, Fitzgerald RH, Jr., Kelly PJ. The depot administration of penicillin $\mathrm{G}$ and gentamicin in acrylic bone cement. J Bone Joint Surg Am. 1981;63:798-804.

31. Hutchison JB, Haraldsson KT, Good BT, Sebra RP, Luo N, Anseth KS, Bowman CN. Robust polymer microfluidic device fabrication via contact liquid photolithographic polymerization (CLiPP). Lab Chip. 2004;4:658-662.

32. Jose B, Antoci V, Jr., Zeiger AR, Wickstrom E, Hickok NJ. Vancomycin covalently bonded to titanium beads kills Staphylococcus aureus. Chem Biol. 2005;12:1041-1048.

33. Kendall RW, Duncan CP, Beauchamp CP. Bacterial growth on antibiotic-loaded acrylic cement. A prospective in vivo retrieval study. J Arthroplasty. 1995;10:817-822.
34. Kharazmi A, Giwercman B, Hoiby N. Robbins Device in Biofilm Research. Methods Enzymol. 1999;310:207-215.

35. Klekamp J, Dawson JM, Haas DW, DeBoer D, Christie M. The use of vancomycin and tobramycin in acrylic bone cement: biomechanical effects and elution kinetics for use in joint arthroplasty. J Arthroplasty. 1999;14:339-346.

36. Ko YG, Kim YH, Park KD, Lee HJ, Lee WK, Park HD, Kim SH, Lee GS, Ahn DJ. Immobilization of poly(ethylene glycol) or its sulfonate onto polymer surfaces by ozone oxidation. Biomaterials. 2001;22:2115-2123.

37. Kuechle DK, Landon GC, Musher DM, Noble PC. Elution of vancomycin, daptomycin, and amikacin from acrylic bone cement. Clin Orthop Relat Res. 1991;264:302-308.

38. Lawson MC, Bowman CN, Anseth KS. Vancomycin derivative photopolymerized to titanium kills S. epidermidis. Clin Orthop Relat Res. 2007;461:96-105.

39. Lawson MC, Hoth KB, Shoemaker R, Bowman CN, Anseth KS. Polymerizable vancomycin derivatives or bactericidal biomaterial surface modification: structure-function evaluation. Biomacromolecules. 2009;10:2221-2234.

40. Maddikeri RR, Tosatti S, Schuler M, Chessari S, Textor M, Richards RG, Harris LG. Reduced medical infection related bacterial strains adhesion on bioactive RGD modified titanium surfaces: a first step toward cell selective surfaces. J Biomed Mater Res A. 2008;84:425-435.

41. Masri BA, Duncan CP, Beauchamp CP. Long-term elution of antibiotics from bone-cement: an in vivo study using the prosthesis of antibiotic-loaded acrylic cement (PROSTALAC) system. J Arthroplasty. 1998;13:331-338.

42. Masri BA, Duncan CP, Beauchamp CP, Paris NJ, Arntorp J. Effect of varying surface patterns on antibiotic elution from antibiotic-loaded bone cement. J Arthroplasty. 1995;10:453-459.

43. McLaren AC, Nelson CL, McLaren SG, DeCLerk GR. The effect of glycine filler on the elution rate of gentamicin from acrylic bone cement: a pilot study. Clin Orthop Relat Res. 2004;427:2527.

44. Nanci A, Wuest JD, Peru L, Brunet P, Sharma V, Zalzal S, McKee MD. Chemical modification of titanium surfaces for covalent attachment of biological molecules. J Biomed Mater Res. 1998;40:324-335.

45. Nelson CL, McLaren AC, McLaren SG, Johnson JW, Smeltzer MS. Is aseptic loosening truly aseptic. Clin Orthop Relat Res. 2005;437:25-30.

46. Neut D, van de Belt H, van Horn JR, van der Mei HC, Busscher HJ. The effect of mixing on gentamicin release from polymethylmethacrylate bone cements. Acta Orthop Scand. 2003;74:670676.

47. Parvizi J, Wickstrom E, Zeiger AR, Adams CS, Shapiro IM, Purtill JJ, Sharkey PF, Hozack WJ, Rothman RH, Hickok NJ. Frank Stinchfield award. Titanium surface with biologic activity against infection. Clin Orthop Relat Res. 2004;429:33-38.

48. Peeters E, Nells HJ, Coenye T. Comparison of multiple methods for quantification of microbial biofilms grown in microtiter plates. J Microbiol Methods. 2008;72:157-165.

49. Penner MJ, Duncan CP, Masri BA. The in vitro elution characteristics of antibiotic-loaded CMW and Palacos-R bone cements. J Arthroplasty. 1999;14:209-214.

50. Penner MJ, Masri BA, Duncan CP. Elution characteristics of vancomycin and tobramycin combined in acrylic bone-cement. J Arthroplasty. 1996;11:939-944.

51. Percival S, Walker JT. Methods used to assess biofouling of material used in distribution and domestic water systems. Methods Enzymol. 2001;337:187-200.

52. Popat KC, Mor G, Grimes CA, Desai TA. Surface modification of nanoporous alumina surfaces with poly(ethylene glycol). Langmuir. 2004;20:8035-8041. 
53. Punyani S, Deb S, Singh H. Contact killing antimicrobial acrylic bone cements: preparation and characterization. J Biomat SciPolym E. 2007;18:131-145.

54. Ruiz-Taylor LA, Martin TL, Zaugg FG, Witte K, Indermuhle P, Nock S, Wagner P. Monolayers of derivatized poly(L-lysine)grafted poly(ethylene glycol) on metal oxides as a class of biomolecular interfaces. Proc Natl Acad Sci USA. 2001;98:852-857.

55. Schaudinn C, Carr G, Gorur A, Jaramillo D, Costerton JW, Webster P. Imaging of endodontic biofilms by combined microscopy (FISH/cLSM-SEM). J Microscopy. 2009;235, Pt. 2:124-127.

56. Sebra RP, Masters KS, Bowman CN, Anseth KS. Surface grafted antibodies: controlled architecture permits enhanced antigen detection. Langmuir. 2005;21:10907-10911.

57. Sebra RP, Masters KS, Cheung CY, Bowman CN, Anseth KS. Detection of antigens in biologically complex fluids with photografted whole antibodies. Anal Chem. 2006;78:3144-3151.

58. Sebra RP, Reddy SK, Masters KS, Bowman CN, Anseth KS. Controlled polymerization chemistry to graft architectures that influence cell-material interactions. Acta Biomater. 2007;3:151-161.

59. Staudt C, Horn H, Hempel DC, Neu TR. Volumetric measurements of bacterial cells and extracellular polymeric substance glycoconjugates in biofilms. Biotechnol Bioeng. 2004;88:585-592.

60. Surman SB, Walker JT, Goddard DT, Morton LHG, Keevil CW, Weaver W, Skinner A, Hanson K, Caldwell D, Kurtz J.
Comparison of microscope techniques for the examination of biofilms. J Microbiol Methods. 1996;25:57-70.

61. van de Belt H, Neut D, Schenk W, van Horn JR, van der Mei HC, Busscher HJ. Staphylococcus aureus biofilm formation on different gentamicin-loaded polymethylmethacrylate bone cements. Biomaterials. 2001;22:1607-1611.

62. Wagner VE, Koberstein JT, Bryers JD. Protein and bacterial fouling characteristics of peptide and antibody decorated surfaces of PEG-poly(acrylic acid) co-polymers. Biomaterials. 2004;25: 2247-2263.

63. Walker JT, Verran J, Boyd RD, Percival S. Microscopy methods to investigate structure of potable water biofilms. Methods Enzymol. 2001;337:243-255.

64. Webster R, Didier E, Harris P, Siegel N, Stadler J, Tilbury L, Smith D. PEGylated proteins: evaluation of their safety in the absence of definitive metabolism studies. Drug Metab Dispos. 2007;35:9-16.

65. Winblade ND, Schmokel H, Baumann M, Hoffman AS, Hubbell JA. Sterically blocking adhesion of cells to biological surfaces with a surface-active copolymer containing poly(ethylene glycol) and phenylboronic acid. J Biomed Mater Res. 2002;59:618-631.

66. Yaniv M, Dabbi D, Amir H, Cohen S, Mozes M, Tsuberi H, Frietkin M, Dekel S, Ofek I. Prolonged leaching time of peptide antibiotics from acrylic bone cement. Clin Orthop Relat Res. 1999;363:232-239. 